\title{
O Direito Ambiental como Ferramenta para o Desenvolvimento Sustentável
}

\author{
Environmental Law as a Tool for Sustainable Development
}

El Derecho Ambiental como Herramienta para el Desarrollo Sostenible

\author{
Renata Andjara Wisniewski ${ }^{1}$ \\ Isonel Sandino Meneguzzo²
}

\begin{abstract}
RESUMO: A presente nota versa a respeito do direito ambiental na interface com o conceito de desenvolvimento sustentável. Foi concebida sob o ponto de vista teórico, amparada no conceito de ecodesenvolvimento. Nesse sentido, o direito ambiental emerge enquanto uma ferramenta para viabilizar o desenvolvimento sustentável, traçando um caminho no sentido de nortear as práticas econômicas, incluindo a elaboração de políticas públicas por parte dos gestores, com o intuito de balizar racionalmente as atividades produtivas. O papel primordial do direito ambiental é regular estas atividades, promovendo o controle de riscos para que se classifiquem dentro de parâmetros toleráveis. Conclui-se que o direito, através das leis, jurisprudências, doutrinas e até mesmo da realidade social, prioriza a positivação do direito ambiental na sua ampla concepção, concentrando elementos das mais diversas áreas, para que sirva como ferramenta com vistas a estabelecer equilíbrio nas relações entre sociedade e natureza.
\end{abstract}

PALAVRAS-CHAVE: Sustentabilidade. Ambiente. Direito.

ABSTRACT: This note deals with environmental law at the between with the concept of sustainable development. It was conceived from the theoretical point of view, supported by the concept of ecodevelopment. In this sense, environmental law emerges as a tool to make sustainable development viable, charting a way to guide economic practices, including the elaboration of public policies by managers, in order to rationally mark the productive activities. The primary role of environmental law is to regulate these activities by promoting the risk control to classify them within tolerable parameters. It is concluded that the law, through laws, jurisprudence, doctrines and even social reality, prioritizes the positivitation of environmental law in its broad conception, concentrating elements from the most diverse areas so that it serves as a tool with a view to establishing balance in relations between society and nature.

KEYWORDS: Sustentatability. Environment. Law.

\footnotetext{
1 Universidade Estadual de Ponta Grossa. Av. Carlos Cavalcanti n 4748 - Uvaranas- CEP 84030-900 - Ponta Grossa - PR. renatawis@hotmail.com.

2 Universidade Estadual de Ponta Grossa. Av. Carlos Cavalcanti n 4748 - Uvaranas- CEP 84030-900 - Ponta Grossa - PR. imeneguzzo@hotmail.com.
} 
RESUMEN: Esta nota aborda el derecho ambiental en la interfaz con el concepto de desarrollo sostenible. Fue concebido desde un punto de vista teórico, apoyado por el concepto de ecodesarrollo. En este sentido, el derecho ambiental surge como una herramienta para hacer viable el desarrollo sostenible, trazando un camino hacia la guía de prácticas económicas, incluida la elaboración de políticas públicas por parte de los administradores, con el objetivo de definir racionalmente las actividades productivas. El papel principal de la ley ambiental es regular estas actividades promoviendo el control de riesgos para clasificarlas dentro de parámetros tolerables. Se concluye que lo derecho, a través de las leyes, la jurisprudencia, las doctrinas e incluso la realidad social, prioriza la positivización del derecho ambiental en su concepción amplia, concentrando elementos de las áreas más diversas para que sirva como una herramienta con el fin de establecer un equilibrio en las relaciones entre sociedad y naturaleza.

PALABRAS-CLAVE: Sostenibilidad. Medio Ambiente. Derecho.

A existência do ser humano sempre esteve condicionada à exploração de recursos naturais. De seu surgimento até os dias atuais, uma caracterização relevante desenvolvida no âmbito da ciência geográfica foi elaborada por Santos, em sua obra intitulada $A$ natureza do espaço: técnica e tempo, razão e emoção. Nesta obra, o supracitado autor pontua três fases: o meio natural, o meio técnico e o meio técnico científico informacional. É a partir do meio técnico, ou seja, a partir da $1^{\text {a }}$ Revolução Industrial, que o equilíbrio entre a extração de bens da natureza e a capacidade da natureza se regenerar começa a ser fragilizado, isto devido às intervenções antrópicas significativas, com emprego de técnicas de mecanização em grande escala. Já o meio técnico-científico-informacional, com início por volta da década de 1970, corresponde à atual fase, na qual as transformações da natureza ocorrem num contexto complexo em que técnica e ciência estão intimamente atreladas aos processos produtivos (SANTOS, 2006).

Nesse sentido, a demanda por recursos naturais e os impactos ambientais adversos aumentaram e surgiu a necessidade de se repensar a relação sociedade e natureza, permeada pelos processos produtivos de grande escala. Portanto, diante de um cenário marcado por degradação ambiental atrelada também a questão da pobreza é que emerge a ideia de harmonizar o desenvolvimento econômico com a garantia de um meio ambiente ecologicamente equilibrado. Para tanto, o caminho inicialmente trilhado foi o da discussão, em âmbito mundial, da questão ambiental. Foi nesse contexto em que o canadense Maurice Strong estabeleceu o conceito de ecodesenvolvimento (SACHS, 2009), procurando caracterizar uma concepção alternativa de política de desenvolvimento, sendo que somente em 1987 foi empregada a expressão desenvolvimento sustentável (BRÜSEKE, 2003).

O desenvolvimento sustentável é definido a partir do Relatório Brundtland como: "[...] aquele que atende às necessidades do presente sem comprometer a capacidade de as gerações futuras também atenderem as suas necessidades" (WORLD COMMISSION ON ENVIRONMENT AND DEVELOPMENT, 1987, p. 54). Tal conceito se enquadra em uma 
perspectiva sistêmica, pelo fato de envolver vários aspectos como políticos, éticos, econômicos, sociais, culturais e ambientais.

De acordo com Sachs (2004) o desenvolvimento sustentável possui cinco pilares. O primeiro pilar, denominado social, é fundamental por motivos intrínsecos e instrumentais, por causa da perspectiva de disrupção social que paira com um caráter ameaçador sobre muitos lugares problemáticos do planeta. O objetivo deste pilar é promover uma melhor distribuição de recursos entre as diversas camadas da sociedade, visando a redução das desigualdades sociais existentes. O segundo pilar mencionado pelo autor é o ambiental com as suas dimensões como os sistemas de sustentação da vida enquanto provedores de recursos e como "recipientes" para a disposição de resíduos. O enfoque deste pilar é pensar em medidas que sirvam para amenizar a utilização dos recursos naturais não renováveis e ao mesmo tempo incentivar o desenvolvimento de outras fontes renováveis, por exemplo: intensificar a pesquisa em busca de novas tecnologias e reduzir o consumo e o volume de resíduos e da poluição. No que tange ao pilar denominado territorial, Sachs (2004) coloca textualmente que este está relacionado à distribuição espacial dos recursos de uma forma mais equilibrada às populações, rural e urbana, e às atividades humanas em geral. O componente econômico a ser observado trata da viabilidade econômica para que as coisas aconteçam, portanto, antes de qualquer medida ser tomada, deve haver um estudo de viabilidade para garantir a eficiência do gerenciamento dos recursos e dos investimentos.

Diante deste contexto, em outra obra, Sachs (2009) argumenta que há três protagonistas ao se pensar em termos práticos no desenvolvimento sustentável: o Estado, a sociedade civil e as empresas devem estar inter-relacionados, com relações simétricas de poder e atuação.

Por fim, e não menos importante, Sachs (2004) menciona o componente político, o qual se fundamenta na governança, pautada em princípios democráticos, tratando-se de um valor fundante e instrumento necessário no cotidiano das pessoas.

Uma das principais dificuldades encontradas atualmente é conseguir viabilizar este desenvolvimento sustentável, fazendo com que não se desvirtue de sua concepção e de seu objetivo original e que não passe a ser um termo banalizado no sentido de mascarar práticas abusivas com caráter unicamente mercadológico. Vale ressaltar a ideia de Souza (2016, p. 309) o qual afirma que:

O grande desafio consiste em buscar o necessário equilíbrio entre o chamado desenvolvimento econômico e a qualidade ambiental. O progresso não tem sido igual à qualidade de vida. Crescimento econômico não significa progresso quando, ao invés de medi-lo pelo método do Produto Interno Bruto - PIB, ele é mensurado pelo Índice de Desenvolvimento Humano - IDH. 
De acordo com o entendimento do autor acima citado, infere-se que o desenvolvimento sustentável deve, antes de tudo, buscar o desenvolvimento humano. Nesta esteira, o direito ambiental surge como uma ferramenta para viabilizar o desenvolvimento sustentável, traçando um caminho para nortear as práticas econômicas, seja na produção de políticas públicas por parte dos gestores, seja para balizar as atividades produtivas. É importante ressaltar que no direito ambiental se consolidam alguns conceitos advindos de outras ciências, para que se possa padronizar o entendimento e a aplicação destes nas diversas áreas de atuação.

O sistema jurídico tradicional comumente era utilizado como alicerce para solucionar conflitos individuais. Com o surgimento de novas demandas decorrentes de complexas relações político-sociais que foram se configurando no contexto do meio técnico-científicoinformacional, o direito passou a se preocupar também com o coletivo. As questões ambientais começaram a ganhar maior atenção, necessitando da ajuda de outras áreas de atuação além das ciências naturais. Desta forma, nasce a proteção aos direitos chamados difusos pelo direito ambiental, sendo estes caracterizados por serem indivisíveis e de titularidade de uma coletividade indeterminada. Quanto ao surgimento do direito ambiental, Souza (2016, p. 291) cita que: "Surge, assim, o Direito Ambiental, entendido como um conjunto de normas jurídicas de diferentes origens, que constituem um microssistema jurídico capaz de assegurar ao ser humano o direito a um meio ambiente equilibrado, essencial à sadia qualidade de vida".

Neste sentido, o direito ambiental surge para garantir um direito fundamental previsto na Constituição da República Federativa do Brasil (1988) a qual foi pioneira em tratar das questões ambientais, destinando um capítulo inteiro ao meio ambiente, além das demais referências nas entrelinhas do restante do texto constitucional.

O artigo 225 da Constituição Federal (BRASIL, 1988) prevê expressamente que: "Todos têm direito ao meio ambiente ecologicamente equilibrado, bem de uso comum do povo e essencial à sadia qualidade de vida, impondo-se ao Poder Público e à coletividade o dever de defendê-lo e preservá-lo para as presentes e futuras gerações".

O legislador também se preocupou em inserir o desenvolvimento sustentável na Lei número 6.938 de 1981 que estabelece a Política Nacional de Meio Ambiente, a qual determina em seu artigo $2^{\circ}$ que:

A Política Nacional do Meio Ambiente tem por objetivo a preservação, melhoria e recuperação da qualidade ambiental propícia à vida, visando assegurar, no País, condições ao desenvolvimento sócio-econômico, aos interesses da segurança nacional e à proteção da dignidade da vida humana (BRASIL, 1981). 
Na sequência, o artigo $4^{\circ}$ define que: "A Política Nacional do Meio Ambiente visará à compatibilização do desenvolvimento econômico-social com a preservação da qualidade do meio ambiente e do equilíbrio ecológico" (BRASIL, 1981). Portanto, como se observou, o desenvolvimento sustentável encontra alicerce tanto nos princípios basilares quanto na legislação ambiental vigente.

Cabe destacar que o direito ambiental é denominado de multidisciplinar, pois se envolve e atua em áreas diversas. Porém, para que possa servir de base para a produção de leis, regulamentações, normativas e portarias, entre outras, deve possuir princípios sólidos que sirvam como parâmetros para a criação e aplicabilidade das normas mencionadas.

Não existe um consenso sobre qual seria o rol taxativo de princípios do direito ambiental, havendo divergências doutrinárias acerca do tema. Em geral, dentre os vários princípios que o norteiam, destacam-se os principais: desenvolvimento sustentável, prevenção/precaução, responsabilização, educação ambiental e ubiquidade (FIORILLO, 2003).

Retomando ao que foi tratado no início do texto, o desenvolvimento sustentável se enquadra como um dos princípios do direito ambiental. Tal princípio, de acordo com Souza (2016), prevê que o Direito e a Economia devem atuar como reguladores das atividades econômicas para que limitem a atuação destas, de modo que não coloquem em risco a vida e as gerações futuras.

Souza (2016, p. 307) ainda cita que "[...] a importância do princípio consiste em situar a defesa do meio ambiente no mesmo plano de importância que outros valores econômicos e sociais protegidos pela ordem jurídica".

Neste sentido, torna-se imprescindível conciliar aspectos como: crescimento econômico, atividades industriais e produtivas, empregabilidade, exploração racional de recursos naturais e conservação da natureza. Apesar de não ser o cerne principal desta nota, cabe destacar também o conceito de governança, o qual em sua interface com o meio ambiente é primordial no contexto do desenvolvimento sustentável. De acordo com Camargo (2008) a governança refere-se a atividades apoiadas em objetivos comuns e partilhados, que abrangem entes governamentais e não-governamentais, mas que só se efetivam se forem aceitos pela maioria, ou, mais precisamente, pelos principais atores sociais de um determinado processo.

À luz destas ideias, entende-se que a atividade econômica sempre gera impactos ambientais, os quais podem vir a resultar em danos. O papel primordial do direito ambiental é regular estas atividades, controlando os riscos para que se classifiquem dentro do parâmetro do tolerável. Sendo assim, qualquer projeto ou política pública permissiva que venha a ser adotada deve nortear-se na sustentabilidade, observando o critério de utilização dos recursos renováveis e não renováveis de modo coerente para que a exploração seja menor do que a capacidade de regeneração e assimilação da própria natureza. 
Por fim, o direito ambiental fez com que o legislador passasse a integrar a busca pela conservação da natureza, sendo responsável por solidificar o elo com os profissionais das ciências naturais, os quais trabalham e estudam as questões ambientais, transformando este resultado em deveres jurídicos que devem ser cumpridos, fiscalizados e eventualmente punidos no plano prático.

Impende destacar que o direito pátrio tem como elemento norteador o fato social, ou seja, o direito é construído de acordo com os anseios, valores e com o próprio clamor social. Partindo desta premissa, conclui-se que o direito, através das leis, jurisprudências, doutrinas e até mesmo da realidade social, prioriza a positivação do direito ambiental na sua ampla concepção, concentrando elementos das mais diversas áreas para que de fato sirva como ferramenta para se efetivar um direito essencial à vida, que é o direito de estar inserido em um meio ambiente equilibrado. Neste sentido, traça parâmetros para que se garanta a continuidade do desenvolvimento econômico de forma controlada com a finalidade de que se perpetue a conservação da natureza sem prejuízo para as gerações futuras.

\section{REFERÊNCIAS}

BRASIL [Constituição (1988)]. Constituição da República Federativa do Brasil. Brasília, DF: Senado, 1988.

BRASIL. Lei no 6.938, de 31 de agosto de 1981. Dispõe sobre a Política Nacional do Meio Ambiente, seus fins e mecanismos de formulação e aplicação, e dá outras providências. Brasília, DF: Presidência da República, 1981. Disponível em:

http://www.planalto.gov.br/ccivil_03/leis/l6938.htm. Acesso em: 20 jun. 2019.

BRÜSEKE, F. J. O problema do desenvolvimento sustentável. In: CAVALCANTI, C.

Desenvolvimento e natureza: estudos para uma sociedade sustentável. São Paulo: Cortez; Recife: Fundação Joaquim Nabuco, 2003. p. 29-40.

CAMARGO, A. Governança. In: TRIGUEIRO, A. Meio ambiente no século XXI: 21 especialistas falam da questão ambiental nas suas áreas de conhecimento. Campinas: Armazém do Ipê: Autores Associados, 2008. p. 307-321.

FIORILLO, C. A. P. Curso de direito ambiental brasileiro. São Paulo: Saraiva, 2003.

SACHS, I. A terceira margem: em busca do ecodesenvolvimento. São Paulo: Companhia das Letras, 2009.

SACHS, I. Desenvolvimento: includente, sustentável, sustentado. Rio de Janeiro: Garamond, 2004.

SANTOS, M. Do meio natural ao meio técnico-científico-informacional. In: SANTOS, M. A natureza do espaço: técnica e tempo, razão e emoção. São Paulo: Edusp, 2006. p. 233260.

SOUZA, P. R. P. Os princípios do direito ambiental como instrumentos de efetivação da sustentabilidade do desenvolvimento econômico. Revista Veredas do Direito, Belo Horizonte, v. 13, n. 26, p. 289-317, maio/ago. 2016. Disponível em:

http://www.domhelder.edu.br/revista/index.php/ veredas/article/view/705. Acesso em: 20 jun. 2019. 
WORLD COMMISSION ON ENVIRONMENT AND DEVELOPMENT. Our common future. 1987. Disponível em:

https://sswm.info/sites/default/files/reference_attachments/UN\%20WCED\%201987\%20Brun dtland\%20Report.pdf. Acesso em: 10 fev. 2020.

Recebido: setembro de 2019.

Aceito: fevereiro de 2020. 